\title{
Embracing Sex Work's Complexity: Global Organizing by Sex Workers
}

\author{
Erika Derkas \\ Sociology and Gender and Women's Studies, New Mexico Highlands University, Las Vegas, USA \\ Email: ederkas@nmhu.edu
}

How to cite this paper: Derkas, E. (2019) Embracing Sex Work's Complexity: Global Organizing by Sex Workers. Open Journal of Social Sciences, 7, 127-138. https://doi.org/10.4236/jss.2019.78010

Received: June 22, 2019

Accepted: August 16, 2019

Published: August 19, 2019

Copyright (c) 2019 by author(s) and Scientific Research Publishing Inc. This work is licensed under the Creative Commons Attribution International License (CC BY 4.0).

http://creativecommons.org/licenses/by/4.0/

\begin{abstract}
In light of atrocities leveled against sex workers in Ipswitch England and the United States the issues of safety, dignity, and violence, both structural and individual, against sex workers globally is a necessary discussion but one rarely given much attention. However, increasingly sex worker advocacy groups, specifically those working from within the industry, have taken up the charge to foster an environment which enables and affirms individual choices and occupational rights. This paper focuses on campaigns coordinated by international and national organizations to complicate deep rooted simplification of sex work by immobilizing the historical association of sex work with dysfunction, drug addiction, organized crime, and powerlessness. The socially constructed notion of sex work is re-claimed and firmly placed in the discourse of work, autonomy, and human rights. Describing the composition of organizing used by numerous activists who are engaged in sex work offers a new way to frame the issues.
\end{abstract}

\section{Keywords}

Reproductive Justice, Sex Work, Human Rights Organizing, Feminism

"Some may say, sex work is not decent. We reply, indecent are the conditions in which we work... Sex workers are not the problem; we are part of the solution" [1]

-(Elena Reynaga, XVII International AIDS Conference Mexico, 2008)

\section{Introduction}

The issue of commercialized sex is an often unsettling and complicated discussion however, one that is long overdue. The organizing efforts by those working within the industry who are mobilizing to legitimize sex work and workers as 
self determining agents, is often ignored. The term sex worker, coined by those working within the industry, came about as a result of challenges to the culturally embedded pathologizing of a certain class of women [2]. It refers to the group of people, female, transgender, male, under-age, immigrant, and native who actively choose to exchange sexual services for money or payment in kind [3] including exotic dancers, sex operators, and masseurs [4]. It is this group which is most vocal and organized and who make up organizations like The Empower Foundation, the New Zealand Prostitutes' Collective (NZPC), Desiree Alliance, Sex Worker Outreach Project (SWOP) and Sex Worker Education and Advocacy Taskforce (SWEAT) of South Africa, among others. They represent contemporary organizations that emphasize the important intersecting relationships between sex workers' human rights, systematic violence, criminalization, poverty, and HIV.

Prostitution has been present in every society that maintains written records [5] [6], however, sex worker rights groups are relatively new to the activist arena. There are over seventy-two rights, advocacy, and sex worker groups mobilized in over eighteen countries as well as international groups organizing transnationally. The challenge to traditional views of prostitutes as sexual slaves, powerless victims, drug addicts, and disposable bodies gained momentum in the 1970s and 80 s as sex workers took it upon themselves to act as their own advocates and vocalize a new concept of prostitution and all commercialized sex, as sex work [7]. Organizations like Empower of Thailand and Desiree of the United States and NZPC of New Zealand promote social awareness through visibility, work towards harm reduction, relegate stigma to the past, and promote the de-criminalization of women's sexuality as a method of enhancing safety and wellbeing of sex workers. Their struggles bring to light the complexity of sex work.

This paper analyzes the position of the various organizations formed and run by sex workers. The analysis focuses on how sex work is conceptualized and what strategies are employed to enhance safety and well being. The analysis is based on face to face interviews with leaders of several organizations, email and video correspondence and website content analysis. Such organizations are part of an international social justice network dedicated to the fundamental human rights of sex workers and their communities, focusing on ending violence and stigma through education and advocacy [8]. Organizations included in the analysis involve the New Zealand Prostitutes' Collective, the Desiree Alliance (USA), the Empower Foundation of Thailand, Bayswan of San Francisco, Sex Worker Outreach Project (USA) and Sex Workers Education and Advocacy Taskforce of South Africa.

\section{Complexity}

The degree of complexity that sex workers face, due in part to their varied economic, immigration, race, gender/sexuality identity and ability issues, leads them to adopt a range of strategies necessary to face a variety of concerns. De- 
spite this, the media and many mainstream feminists perpetuate the belief that all sex workers have similar experiences. All too often the focus lies squarely on violence and exploitation.

The resulting script written for women, especially women of color, trans folks and women of the global south working within the sex industry, is a narrow one. Near exclusivity in research historically focused on the individual in an attempt to delineate the causal factors contributing to entrance into the sex industry. Such factors include a history of sexual violence and molestation, drug addiction, and family dysfunction [9]. The individual as a cause of a problem is an argument that is easier to sustain than creating awareness of the possibilities and opportunities that are veiled by socially constructed meanings and institutional arrangements [10]. More recently research focuses on structural issues such as global economic stratification which creates conditions whereby sex work is one a few options offered individuals in the global south [11] [12]. In either case, the analysis assumes the vulgarity of sex work and thus reinforces the notion that workers themselves are either damaged bodies or helpless victims. In this discourse, there is a tendency to distill a problem down to its least common denominator in order to create a simple solution that seems reasonable and achievable. The more simplified the understanding the more distorted the reality women and trans folks face becomes. This tendency exposes societies' and governments' unwillingness to address complex issues.

Misconceptions regarding a uniform experience emerged in part due to the contemporary penological discourse, which moves away from understanding "deviance" and its socially constructed nature and employs what [13] term "actuarial justice". Under actuarial justice "deviant" behavior is not examined, rather it is assumed and identifying, classifying, and managing groups based on an assessment of their level of danger posed to society becomes central [13]. In turn, the management of criminal behavior involves risk profiles used to classify whole groups of individuals rather than investigating the complexity of individual cases. Thus, under this discourse the assumed nature of sex work is informed by well established notions about those involved in the industry and leads to obscured understandings.

Simpler approaches are attractive, but they lead to the treatment of individuals as tools or diseases, assuming that social issues can be fixed by technological manipulation like criminalization. Sex worker activists use such opportunities as a springboard to contest simplified understandings about sex work to create societal awareness of its complexity. Activists move away from these simplistic discussions and explanations of why individuals enter the commercialized sex industry in order to pinpoint the issues that, from their standpoint, contribute to the realities of exploitation and violence among others.

\section{The Intersections of Criminalization, Stigma, Violence, and Organizing}

Many organizations like Empower Foundation, Desiree, and SWEAT do not 
deal with violence as a separate and unique issue which women and trans folks in the industry face. Rather broader issues believed to be central to understanding violence as consequence are focused upon including economic, political, and cultural issues. Criminalization, stigma, and discrimination intersect to create an environment where violence is prevalent and in many cases publicly accepted which ultimately undermines the entire health and wellbeing of workers. Therefore, much of the organizing efforts involve simultaneously addressing each factor (see Figure 1). Each of the factors, e.g. organizing, mechanisms, factors and outcomes with their subcategories are discussed in detail below.

\section{Organizing Efforts, Mechanisms, Factors and Outcomes}

The organizing efforts of sex workers revolve around visibility and the development of a discourse which involves framing the issue as labor concerns and the struggles of workers to obtain safe, healthy and just workplaces. Workers, especially the most vulnerable workers i.e. sex workers, particularly those who are undocumented, transgender and/or people of color, are often besieged by stig$\mathrm{ma}$, violence, exploitation and police oppression.

The mechanisms for achieving the outcomes of a re-written script centralizing labor rights, health, and wellbeing include creating organizations and an overall movement that is led, run, and developed by those working within the industry to ensure self-determination, self-regulation, and autonomy. Through visibility, education (both within the industry and for the mainstream public) and selfdetermined discourse the stigma and violence is argued to be addressed more honestly and effectively.

\section{De-criminalization}

The fight against criminalization according to [14] began in Lyons, France, when in 1975, prostitutes made a list of grievances with a specific plea for protection from police harassment and repression. Such conditions arose from a revision in French prostitution laws which thrust them into the streets and thus made them vulnerable to physical assaults and arrests [14]. The sustained effort to enhance the status of sex workers, beginning in France, bourgeoned into an international movement.

The central goals to dismantle public designations of deviance for sex workers and systems of legal and social control [15] has met with a great deal of resistance. This is especially the case as we live in a society dominated by an aggressive law enforcement regime that is increasingly accepted by the mainstream.



Figure 1. Anatomy of organizing. 
The move to decriminalize sex work is often conflated with the notion of legalization. Activists advocate for the decriminalization for several reasons while also addresses the limitations. Clarification of the two concepts demonstrates why one is promoted over the other.

Legalization refers to the use of criminal laws to regulate or control the sex industry by setting the legal directives for its operation [16]. Legalization varies significantly from rigid regulation by the state to privatization of the industry within a legally defined framework. Strict criminal penalties for the sex industry businesses that operate outside the legal framework accompany the legalization framework.

Nevada's legalized system of prostitution is often highlighted as a model for state legalization. However, as many national advocacy groups point out, workers lack agency over their working conditions. Thus, it appears that one system of exploitation is exchanged for another [17].

Through decriminalization all criminal laws having to do with the sex industry's operation are removed. This model, supported by many sex worker advocates, seeks to sustain occupational health and safety and workplace issues using standard legal and workplace means [16].

Many within the industry argue that criminalization is one of the key mechanisms sustaining other factors that sex workers must struggle against. Criminalization leads to increased amounts of violence, occupational hazards, and exploitation of women within the industry. Partially this is due to the culturally embedded stigma and partially through its unregulated nature. In a context of criminalization, the violence experienced emerges from four main sources: the criminalization of sex work; the worker environment (which is largely unregulated); the pathologizing and marginalization of female sex workers, i.e. stigma associated with sex work; and finally, a general devaluation of women and trans folks within certain cultural contexts, which combined creates an arena where workers are treated as disposable bodies.

Since much of sex work is criminal it is therefore considered a social problem to be handled by the state through penalization. The way individuals think and interpret the social world is partially influenced by how social problems are defined especially as we come to view many of the conditions as deplorable [18]. To name a phenomenon a social problem means to begin a process where particular discourses form and decisions about policy are considered. The language and rhetoric of social problems operates on the assumption that there exists a basic consensus about the character of the condition that is detested. In other words, social construction of problems, and not nature, brings about the assumptions that inform public consensus. Such conceptualizations in turn foster both societal and internalized stigma.

The increase in complications women must face is demonstrated in the fact that marginalizing and stigmatizing sex workers does little to assist in HIV \& AIDS prevention efforts. Constant police harassment and societal prejudice hamper sex workers' ability to gain clear information on HIV and safer sex. 
Furthermore, prejudicial healthcare workers limit condom accessibility and overall health care. Consequently, fear of discrimination following the disclosure as a sex worker and possible legal recrimination, limit sex workers' ability to access appropriate healthcare and social services.

The stigmatization furthermore, that sex workers face has created fertile ground for society and public authorities to condone violence and crime against sex workers because it is seen as inherent to the work. Discrimination and prejudice against sex workers by the public comes about in the form of outspoken intolerance and verbal abuse. Adult commercial sex workers are regarded as outsiders to the majority of communities in which they work. As a result of the criminalized status in society and by the fact that they are usually women, sex workers are particularly vulnerable to all crimes of violence against women.

The increased risk to health and well being is also partially due to its illegal nature, which is unregulated. An unregulated system, i.e. one without formal oversight, brings about abuse and violations of women working within the industry, originating from police, middlemen, and clients.

The unregulated worker environment is generally a space where men are given visual and physical access to certain women and often inadvertently that access is misconstrued to mean that it is acceptable to invade her in any manner. The type of violence may include rape by potential customers, club owners or workers, hitting and punching, and or verbal abuse like being called a cunt or whore. This misinterpretation is further coupled with the stigmatization associated with women in the industry and in turn fosters a climate where women viewed as disposable bodies, are susceptible to a hostile environment where violence may ensue.

These types of dangers have been garnering national and international attention. In the United States three white Duke University lacrosse players charged with rape and sexual abuse of an African American exotic dancer were dismissed. Women disappeared and ended up victims of a serial killer's fantasy killing spree in Ipswitch, England. "Thirty-four sex workers were killed in Latin America in the ten months between November 2007 and August 2008 alone: All with complete impunity. In Bolivia sex workers were publically lynched in 2008 and in the Congo and Cambodia there is evidence of systematic rape of sex workers by security forces" [1].

In any cultural setting where women are devalued to begin with, the lack of respect for the profession, the stigmatization and discrimination that continues, raises obstacles for the participation of members in community interventions. Furthermore, internalized stigma further complicates the ability to foster empowering experiences and rather promotes fatalistic expectations that not much can be done. What appears clear to sex worker activists is that their proposition to manage the industry substantially increases sex workers physical well being.

\section{Visibility}

In addressing these complex issues, sex worker advocates utilize visibility as a means to improve the conditions identified as barriers to self-determined, res- 
pected, and healthy working conditions. Visibility, a strategy that allows women within the industry to rewrite the script of damaged bodies, is achieved on many levels including: engaging in feminist debates, organizing celebrations/festivals conferences, developing web-sites, designing innovative nonviolent civil disobedience, theatre, art, sophisticated media work, and direct action (see Figure 2). Visibility creates awareness that raises public consciousness about the diversity of concerns, experiences, and identities that sex work encompasses. By doing so sex workers create a space to legitimize the work as labor, to publically embrace the sex worker identity, and in turn dismantle societal stigma.

\section{Engaging Mainstream Feminists}

The specific content of the theoretical backdrop to feminist organizing around this particularly contentious issue, has been the subject of intense debate and acrimony in feminist writings [19]-[29] and is beyond this discussion. However, to simplify matters, I propose to divide the debate into two basic camps: anti-pornography feminists (historical term) or abolitionists who advocate for the total eradication of prostitution in particular and sex work in general. On the other end of the spectrum are sex worker advocates/sex positive feminists who demand better conditions related to the work environment. Central to this debate is the dichotomous consideration of whether sex work is a matter of choice, preference and self determination or whether it is part of an industry that exploits and degrades women.

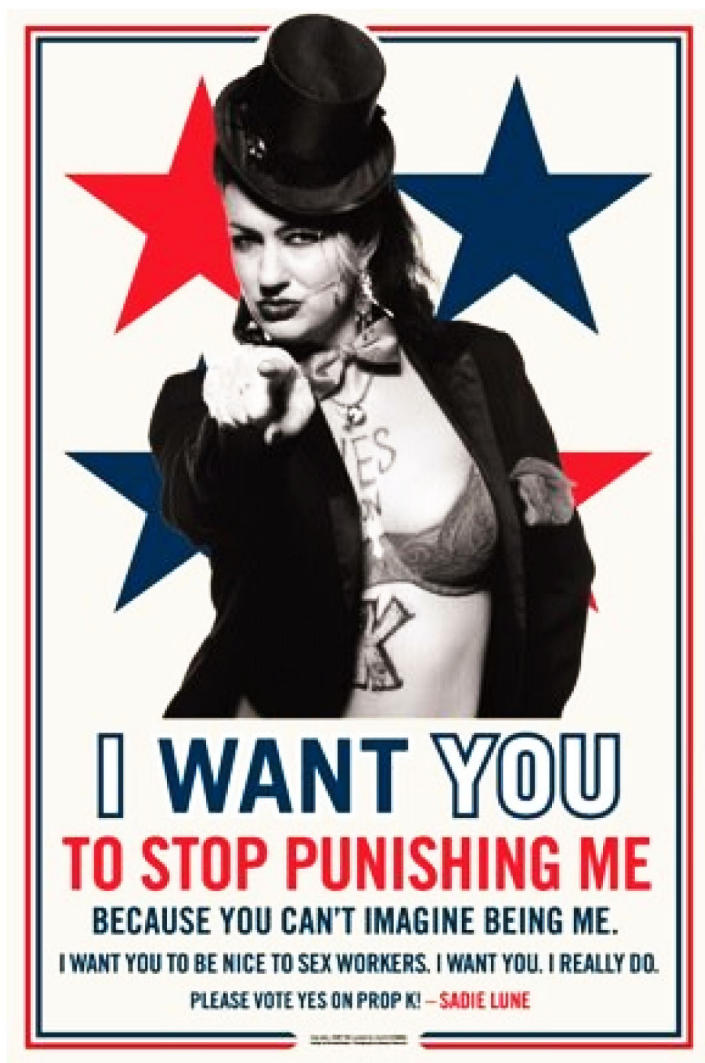

Figure 2. By Sadie, Artist and Winner of Tony Labat's SFMOMA's "I Want You" project. 
From the view of anti-pornography feminists, commercial sex is a signifier of women's oppression. Catharine MacKinnon states, "in the past, we had a women's movement which understood that the choice to be beaten by one man for economic survival was not a real choice, despite the appearance of consent a marriage contract might provide... Yet now we are supposed to believe, in the name of feminism, that the choice to be fucked by hundreds of men for economic survival must be affirmed as a real choice, and if the woman signs a model release there is no coercion there" [30].

Mainstream white feminist scholars and activists proposing censorship or abolition, are often criticized for dominating the current debates, lacking an understanding of the complexity of the issues, and perpetuating stigma of sex workers. Activists are challenging mainstream feminism on their moralistic superiority, colonial mentality, and disregard for the concerns of women of color, poor women, trans people, and women of the global south working within the industry.

This critique is embedded in the commitment for self determination and autonomy, for it has been sex worker activists who are leading the charge in organizing, in the articulation of their concerns, and in the development of approaches to address those concerns. First and foremost the identity as sex workers is embraced and recognized as a viable option. Moving away from a discourse of threatening and volatile bodies, activists reclaim their humanity and thus define the demands of sex workers as human rights (see Figure 3 ). The idea that sex workers have rights which must be respected and protected is vigorously asserted. The reclaiming of identities dissociates from the socially constructed persona of fallen women and the self-identified "bad girls" to workers who are active in their rights' movement. Through the reclamation of their identity women revolutionize the role of movement activists with a genuine passion to achieve rights guaranteed all human beings, citizens, women, and workers.

In this regard, activists have engaged in the contemporary ongoing feminist debates on women's rights to oversee and control their bodies in the way they see fit. By doing so they have been successful in linking the issues sex workers face with the issues of women globally. Connections are made to the oppression experienced by other groups especially those who have been politically successful

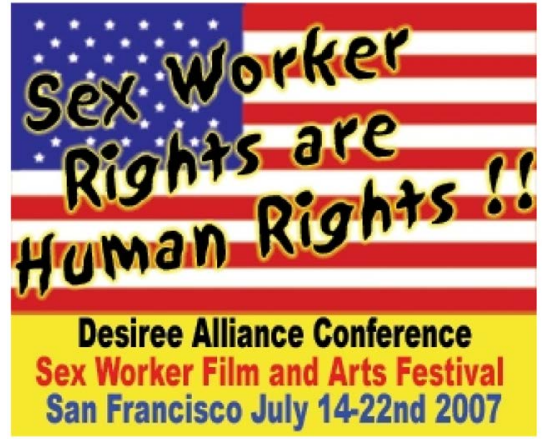

Figure 3. Artist: Carol Leigh, Designed 2007 Bayswan http://www.bayswan.org/ . 
and by focusing in on the accomplishments evidenced by work done within the sex industry. The approach allows for women to relate to the positive and material context which makes change realistic and practical.

Sex work advocates consider sex work legitimate acts of labor and that contributes to the economy of any given culture. Many organizations highlight the contributions that sex work has made to various economies in an attempt not only to create public awareness of sex works steadfastness but its legitimate role in the sustainability of economies.

For instance, the Empower Foundation engenders a clear understanding of how the sex industry contributes to Thailand's struggling economy. They document the earliest record of the state directly profiting from prostitution in Thailand that occurred in 1680 [31]. At such time a Thai official was licensed by the state to run an elite brothel in Ayutiyha, with all proceeds reverting back to the state. Six hundred women worked in the establishment, many of whom were the daughters of esteemed officers. Both workers and brothel owners paid taxes, contributing substantial amounts to the state. Moreover, customers included local and foreign dignitaries, sailors, and traveling merchants [31].

For centuries, the state gained more income from taxes on brothels than gambling houses. Prostitution became illegal in 1960, curiously at the same time that the Tourism Authority and Thai airways began, suggesting that both institutions benefited immensely from the revenue generated from sex work.

\section{Education}

Education among sex workers plays a crucial role in the organizing efforts of the various groups discussed. Activists recognize that economic factors often contribute to the increased vulnerability of women and trans folks in general. For instance, the economic downturn faced by Thailand, has been correlated to an increase in sex work among young people; Since the downturn in 1996 a ten percent decrease in school enrollment at the primary school level has occurred. Unemployment is high so there is very little opportunity for work in the formal sector. In turn, there has been an increase in jobs in the informal sector. According to Ehrenreich [32] women tend to occupy the majority of informal sector positions.

Therefore, organizations actively pursue educational opportunities for those working in the sex trade. They approach education in a very practical and applied manner. Currently, for instance, The Empower Foundation established four educational centers throughout Thailand that are designed and run by Empower Foundation sex workers. Empower has over thirty thousand sex workers over the last two decades. SWEAT's main focus is on addressing HIV infection and STD's among the sex working population through advocacy, education, counseling, and support [33]. Limited education and language barriers as well as the social, legal and cultural stigma and discrimination that sex workers have to cope with hamper healthcare workers from reaching this hard to reach population. Many of the women have never been able to access education and have done so for the first time through organizations like Empower and SWEAT. 


\section{Conclusions}

One of the more disturbing consequences resulting from criminalization and problematizing sex work is the belief that violence, instability, and other social problems are rooted in female sexuality. This simplification implies that women are the culprits of persistent poverty, crime, and moral shortcoming as they are "(mis) represented as hyper fertile bodies, promiscuous [vixens] populating the world like unspayed animals" [34]. The underlying message is poverty and attendant problems like prostitution, are too complex to address; it is much simpler to control [i.e. incarcerate] the bodies of women and trans folks from certain threatening populations.

One conclusion that can be gleaned from this analysis is that interventions that attempt to challenge stigma and discrimination through the creation of conceptual alternatives best coincide with concrete changes to the conditions that produce violence. These include education of communities that specifically deal with stigma, racism, sexism, structural changes within the environment that allow violence to fester and connecting organizations formed by sex workers actively engaged in voicing the concerns of those working within the industry. This approach promotes true agency in determining how problems are conceptualized and addressed.

Secondly, the terms empowerment and participation have been used frequently within the literature related to international development but lack a nuanced definition. For the most part the terms have been used simplistically and indiscriminately as determined by a matter of degree, more or less participation, more or less empowerment. However, workers within the industry offer a more in depth understanding that moves us beyond tokenism to genuine devolving of power to the community. A more qualitative understanding of empowerment and participation that can be generated from organizations like the Empower Foundation, Desiree and Bayswan is necessary for understanding the different types of activities. These organizations conceptualize participation in concrete terms of action in which women may be empowered to take part.

As a final note, I think for those who are advocates for women working within the industry it is important to embrace qualitative research projects that allow the voice of women to truly take form. To improve on future studies, one approach is to adopt a community participatory perspective which includes participant engagement, individual and group interviews, and a more reproductive justice approach which involves participants in the final writing process of any report generated from such inquiry [35] [36].

\section{Conflicts of Interest}

The author declares no conflicts of interest regarding the publication of this paper. 


\section{References}

[1] Reynaga, E. (2008) Sex Workers Are Part of the Solution: Women, Rights and Change. http://katehardy.wordpress.com

[2] Yuran, N. (2017) Finance and Prostitution: On the Libidinal Economy of Capitalism. Differences, 28, 136-165. https://doi.org/10.1215/10407391-4260567

[3] Sloan, J. (2000) Overview of Issues Affecting the Adult Commercial Sex Work Industry, Conference Proceedings. http://www.sweat.org

[4] Delacoste, F. and Alexander, P. (1987) Sex Work: Writings by Women in the Sex Industry. Cleis Press, San Francisco.

[5] Bullough, V. and Bullough, B. (1978) Prostitution: An Illustrated Social History. Crown Publishers, New York.

[6] Lerner, G. (1986) The Creation of Patriarchy. Oxford University Press, New York.

[7] du Plessi, G. (1992) Splendors and Miseries. New York Review, July 16, 31-35.

[8] Sex Workers Outreach Project (2008) Sex Workers Outreach Project-East. https://swopusa.org/

[9] Farley, M. (2004) Bad for the Body Bad for the Heart: Prostitution Harms Women Even If Legalized of Decriminalized. Violence against Women, 10, 1087-1125. https://doi.org/10.1177/1077801204268607

[10] Johnston, H. and Klandermans, B. (1995) Social Movements and Culture. University of Minnesota Press, Minneapolis.

[11] Bales, K. (2002) Because She Looks Like a Child. In: Ehrenreich, B. and Hochschild, A., Eds., Global Woman: Nannies, Maids, and Sex Workers in the New Economy, Henry Holt and Company, New York, 207-229.

[12] Flowers, R. B. (1998) Prostitution of Women \& Girls. McFarland Company Press, Jefferson.

[13] Feeley, M. and Simon, J. (1994) Actuarial Justice: The Emerging New Criminal Law. In: Nelken, D., Ed., The Futures of Criminology, Sage Publisher, London, 173-201.

[14] Hobson, B.M. (1987) Uneasy Virtue: The Politics of Prostitution and the American Reform Tradition. Basic Books, New York.

[15] Jenness, V. (1993) Making It Work: The Prostitutes' Rights Movement in Perspective. Aldine de Gruyter Publishing, New York.

[16] BAYSWAN (2017). http://www.bayswan.org/defining.html

[17] Call off Your Tired Ethics (2017) Decriminalization vs. Legalization: Prostitution Decriminalization vs. Legalization-What's the Difference? http://www.freedomusa.org/coyotela/decrim.html

[18] Gusfield, J. (1989) Constructing the Ownership of Social Problems: Fun and Profit in the Welfare System. Social Problems, 36, 431-441. https://doi.org/10.2307/3096810

[19] Morgan, R. (2001) The Demon Lover: The Roots of Terrorism. Washington Square Press, Washington DC.

[20] Hughes, D.M. and Roche, C.M. (1999) Making the Harm Visible. Global Sexual Exploitation of Women and Girls Speaking Out and Providing Services. The Coalition against Trafficking in Women, Michigan.

[21] MacKinnon, C.A. and Dworkin, A. (1998) In Harms' Way: The Pornography Civil Rights Hearings. Harvard University Press, Cambridge.

[22] Dworkin, A. (1997) Life and Death. Free Press, New York. 
[23] Bindman, J. and Doezman, J. (1997) Redefining Prostitution as Sex Work on the International Agenda. http://www.walnet.org/csis/papers/redefining.html

[24] Leidholdt, D. (1993) Prostitution: A Violation of Women's Human Rights. Cardozo Women's Law Journal, 1, 133-147.

[25] Willis, E. (2012) Beginning to See the Light. University of Minnesota Press, Minneapolis. https://doi.org/10.5749/minnesota/9780816680788.001.0001

[26] Juno, A. and Vale, V. (1991) Angry Women: RE/Search. Juno Books, New York.

[27] Bright, S. (2004) Mommy's Little Girl: Susie Bright on Sex, Motherhood, Pornography, and Cherry Pie. Thunder's Mouth Publishing, New York.

[28] Rubin, G. (1984) Thinking Sex: Notes for a Radical Theory of the Politics of Sexuality. In: Vance, C., Ed., Pleasure and Danger, Routledge \& Kegan, Paul, London, 267-319.

[29] Rubin, G. and Califia, P. (1981) Sadomasochism: Fears, Facts, Fantasies. Gay Community News, 9, 8-9.

[30] MacKinnon, C.A. (1993) Prostitution and Civil Rights. Michigan Journal of Gender \& Law, 1, 13-31.

[31] The Empower Foundation (2016). http://www.empowerfoundation.org

[32] Ehrenreich, B. and Hochschild, A. (2002) Global Woman: Nannies, Maids, and Sex Workers in the New Economy. Henry Holt and Company, New York.

[33] Sex Workers Education and Advocacy Taskforce (2017). http://www.walnet.org/csis/groups/sweat/index.html

[34] Bordo, S. (1998) Are Mothers Persons? Reproductive Rights and the Politics of Subjectivity. In: Rogers, M.R., Ed., Contemporary Feminist Theory, McGraw Hill, Boston, 227-245.

[35] Ross, L., Roberts, L., Derkas, E., Peoples, W. and Bridgewater, P. (2017) Radical Reproductive Justice: Foundations, Theory, Practice and Critique. Feminist Press, New York.

[36] Ross, L. and Solinger, R. (2017) Reproductive Justice: An Introduction. University of California Press, Berkeley. 